\title{
SUSTAINABLE COAL SUPPLY CHAIN MANAGEMENT USING EXERGY ANALYSIS AND GENETIC ALGORITHM
}

\author{
Reihaneh NADERI, Mohsen SHAFIEI NIKABADI \\ Semnan University, Semnan
}

Akbar ALEM-TABRIZ

Shahid Beheshti University, Tehran

Mir Saman PISHVAEE

School of Industrial Engineering, Iran University of Science and Technology, Tehran

\begin{abstract}
:
Environmental threats of coal usage in the electricity production combined with the consumption of renewable and non-renewable resources had led to worldwide energy challenges. The cost of coal mining and economical and environmentally sustainable usage of mined coal could be optimized by efficient management of coal supply chain. This paper provides a mathematical model for improving coal supply chain sustainability including the cost of exergy destruction (entropy). In the proposed method, exergy analysis is used to formulate the model considering not only economic costs but also destructed exergy cost, while genetic algorithm is applied to efficiently solve the proposed model. In order to validate the proposed methodology, some numerical examples of coal supply chains are presented and discussed to show the usability of the proposed exergetic coal supply chain model and claim its benefits over the existing models. According to the results, the proposed method provides $17.6 \%$ saving in the consumed exergy by accepting $2.7 \%$ more economic costs. The presented model can be used to improve the sustainability of coal supply chain for either designing new projects or upgrading existing processes.
\end{abstract}

Key words: coal supply chain, exergy, genetic algorithm, sustainability

\section{INTRODUCTION}

Ecosystems provide the basis for development of human community and sustainable industries. Energy supply is a fundamental component of industrial processes which widely impacts ecosystems, degrades them, and generates environmental pollutions. Therefore, minimization of energy consumption is a main step toward environmental protection. Moreover, the consumed energy should be supplied from sustainable resources [1]. The efficiency and quality of the energy supply can be modelled using exergy analysis [2]. Exergy is a thermodynamic concept used to measure the performance of processes aims at increasing the efficiency of energy utilization and quantifying the magnitude of losses [3].

In spite of recent developments to extract energy from renewable sources [4], coal fired power plants will continue to be operational for next decades to meet the worldwide energy demand [5]. Coal is the most important component for electricity production. Approximately $53 \%$ of the electricity produced in USA is provided by coal, while $92 \%$ of extracted coal is used for electricity production [6].
However, the amount of coal used to produce electricity is expected to rise due to growth in demands [7]. With such an increasingly competitive coal industry, it is highly required to develop efficient methods to minimize the overall cost for the sustainable coal supply chain management (mining, transportation, and power plant), while meeting required environmental standards and regulations [8].

Considering environmental risks and impacts of the coal mining, the performance of the whole process is one of the major concerns for the involved parties [9]. In addition to the economic costs of coal supply chain (e.g., miners, washing plants, transporters, and power plants), there are other costs related to environmental impacts and pollutions which should be taken into account within the total operational costs of the system [8]. Any industrial process including the mitigation of indirect costs such as environmental impacts, is known as a sustainable process. Sustainability in coal supply chain is more complex as it suffers from other implications such as ethical and social risks. 
Environmental impacts of the coal usage in power generation, high production costs, and more importantly, environmentally sustainable coal usage has been discussed in many researches $[2,10,11,12,13,14,15,16]$. Man-Zhi et al. [11] proposed a method based on object-oriented petri net (OPN) to model coal supply chain operation flow. Yang et al. [2] have extended a framework to quantify purchased resources and pollutant emissions of industrial production processes by integrating the resource, economic, and environmental factors in a coal industry. Aniokete et al. [10] discussed the environmental impacts of the coal fly ash, waste industrial brine, and waste cooking oil within coal supply chain to achieve sustainable coal supply chain. Pan et al. [13] illustrated the existing challenges in coal supply chain. They provided some technical information about environmental effects and pollution from the coal mining, preparation, to the final conversion for power generation. Thomas et al. [14] examined a resource constrained production planning and scheduling problem within a coal supply chain. They considered multiple independent producers with a single linking constraint. They presented a mathematical model and solved it using Lagrangian relaxation.

\section{Our contributions}

Although many researches have been proposed for sustainable coal supply chain management, the researchers who used the exergy concept, mostly have considered the resource side of life cycle assessment (LCA) and paid less attention to economic investment and environmental impacts of coal supply chain. The main purpose of this paper is to reduce the destructed exergy in the coal supply chain model, in order to assist coal supply chain decision makers toward more sustainable processes. To achieve this purpose, a new mathematical model for sustainable coal supply chain management considering economic and exergetic costs is formulated using exergy analysis. In order to efficiently solve the established NP-hard model, genetic algorithm (GA) is utilized. Our contributions in this paper can be summarized as follows:

- Modeling of sustainable coal supply chain management considering the destructed exergy (entropy) to remark the importance of disorders and environmental aspects on achieving more sustainability.

- Formulation of the sustainable coal supply chain model as a multi-objective optimization problem in terms of economic and exergetic cost.

- Utilizing genetic algorithm to optimize the established model.

- Encoding of feasible solutions using a combined binary-integer structure to simultaneously optimize different size/type decision variables.

- Performance evaluation of the proposed method on three numerical examples.

The rest of the paper is organized as follows. Problem definitions are described in section 2 . The mathematical model and solution method are presented in Section 3 and 4 , respectively. Simulation results of the proposed method and comparison with existing techniques are provided in Section 5. Finally, Section 6 concludes the paper following with future research directions.

\section{LITERATURE REVIEW}

The main waste gas emissions are $\mathrm{CO}_{2}, \mathrm{SO}_{2}, \mathrm{NO}$ and smoke dust that can damage Ozon layer, make acid rain and contribute to the global warming [17]. According to the global pollution statistics published by International Energy Agency at 2015 , over $43 \%$ of $\mathrm{SO}_{2}, 13 \%$ of $\mathrm{NO}$, $39 \%$ of $\mathrm{CO}_{2}$ and $7 \%$ of the fine particulate matter come from the coal [18]. Not only coal burning, but also coal mining results in overburden waste in air and water resources. Therefore, studying about the environmental implications of coal production and consumption is an important issue [19].

There are different steps in coal supply chain from mining raw coal to delivering it to the real consumers. These steps can be summarized in Fig. 1. Coal mining operations comprise blasting, cutting, drilling, loading, ventilation, drainage, lighting, and portaging [20]. The coal preparation includes coal washing and some processing steps such as size reducing of the mined coal and removing rocks, ash-forming materials, and ultrafine coal. Commercial coal logistics involve sales department, transportation and warehousing at customer centers. These centers are linked via logistics flow and capital flow [21].

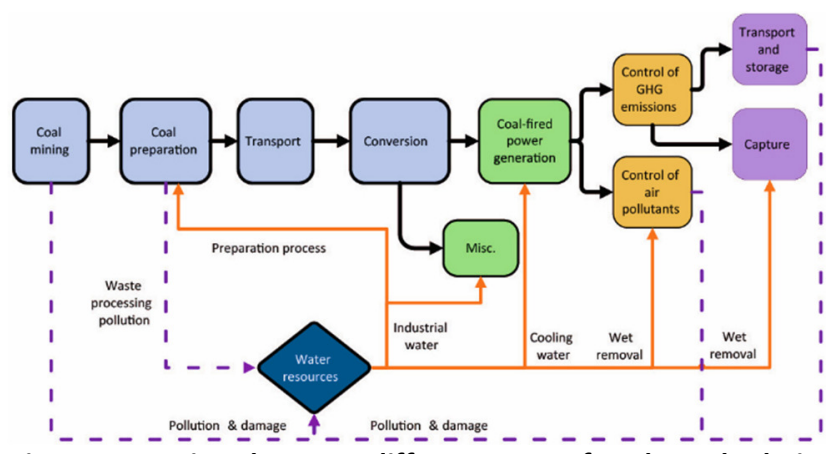

Fig. 1 Interactions between different steps of coal supply chain Source: based on [13].

Coal cleaning process may vary due to the characteristics of the raw coal, available equipment, and the required quality of the cleaned coal. In order to separate coal from the ash, different technologies are available, which most of them are based on the gravity disparity of coal and ash. Some use flotation concept which is based on the disparity in surface properties of coal and ash [22]. The choice of cleaning technology has implications on the total performance of the coal supply chain, i.e., resources, economic, and environmental (exergetic) costs.

\section{RESEARCH METHODOLOGY}

In the majority of previous studies within the area of coal supply chain management, the intention of the cost is workflow related cost elements and not the indirect costs and disorders. In this paper, the destructed exergy (entropy) cost is also included into coal supply chain cost function using exergy analysis. The aim is to establish a 
mutually beneficial relation between enterprise and the resource, economic and environmental performance. To achieve this purpose, the sustainable coal supply chain management is considered as a multi-objective optimization problem comprising eight objective functions for minimization of economic costs as well as exergetic cost. The list of the indices, parameters, and decision variables of the proposed sustainable coal supply chain model can be summarized in Table 1.

\section{Coal supply chain model}

The supply chain model used in this paper is a four-stage coal supply chain include mines, washing plants, warehouses, and customers, which can be seen in Fig. 2. At first, the coal is extracted, and then, coal processing is done at mining sites. During the coal preparation step, the coal is processed and cleaned from unwanted materials such as dirt, ash, sulfur, and rock. These processes increase the heating value of the coal. The prepared coal is transported to warehouses to be delivered to target customers. Although in some cases, there are demands for raw coal which should be directly delivered from the mine; this scenario is not considered at the proposed model. The goal of this model is to satisfy customers' demand, balance the flow at the network facilities, fulfilling the capacity constraints, and meeting the logical constraints.

Table 1

List of indices, parameters, and decision variables

\begin{tabular}{|c|c|}
\hline Index & Definition \\
\hline $\bar{i}$ & Mine index, $i=1,2,3, \ldots, I$ \\
\hline j & Coal preparation center (washing plant) index, $j=1,2,3, \ldots, J$ \\
\hline$p$ & Product index, $p=1,2,3, \ldots, P$ \\
\hline$w$ & Warehouse index, $w=1,2,3, \ldots, W$ \\
\hline$k$ & Customer index, $k=1,2,3, \ldots, K$ \\
\hline Parameter & Definition \\
\hline$\overline{f_{i}}$ & Fixed cost of coal mine $i$ \\
\hline$f_{j}$ & Fixed cost of coal washing plant $j$ \\
\hline$f_{w}$ & Fixed cost of coal warehouse $w$ \\
\hline$\alpha_{p i}$ & Raw coal capacity of mine $i$ of product $p$ \\
\hline$\alpha_{p j}$ & Coal washing plant $j$ capacity of product $p$ \\
\hline$\alpha_{p w}$ & Coal warehouse $w$ capacity of product $p$ \\
\hline$Y_{p i}$ & Unit raw coal cost of product $p$ supplied by mine $i$ \\
\hline $\bar{\gamma}_{p i}$ & Unit market purchase price of raw coal of product $p$ supplied by mine $i$ \\
\hline$\gamma_{p j}$ & Unit coal washing cost of product $p$ manufactured by coal washing plant $j$ \\
\hline$\gamma_{p w}$ & Unit coal warehouse cost of product $p$ at warehouse $w$ \\
\hline$h_{p j}$ & Unit holding cost of product $p$ at washing plant $j$ \\
\hline$h_{p w}$ & Unit holding cost of product $p$ at warehouse $w$ \\
\hline$\tau_{i j}$ & Unit freight rate from mine $i$ to coal washing plant $j$ \\
\hline$\tau_{j w}$ & Unit freight rate from coal washing plant $j$ to warehouse $w$ \\
\hline$\tau_{w k}$ & Unit freight rate from warehouse $w$ to customer $k$ \\
\hline$r_{i j}$ & Distance between mine $i$ to coal washing plant $j$ \\
\hline$r_{j w}$ & Distance between coal washing plant $j$ to warehouse $w$ \\
\hline$r_{w k}$ & Distance between warehouse $w$ to customer $k$ \\
\hline$D_{p k}$ & Demands of customer $k$ for product $p$ \\
\hline$C_{p}$ & Unit selling price of product $p$ to customers \\
\hline$C_{p 0}$ & Unit market price of the product $p$ \\
\hline$I_{p j}$ & Inventory of product $p$ at washing plant $j$ after product transferring to warehouses \\
\hline$I_{p w}$ & Inventory of product $p$ at warehouse $w$ after product transferring to customers \\
\hline$\partial$ & 1 if entropy is accounted; 0 otherwise \\
\hline Ex dest & Amount of destroyed (wasted) exergy \\
\hline$S_{\text {gen }}$ & Entropy generated \\
\hline$T_{0}$ & Environmental temperature \\
\hline$S H_{p j}$ & ash of commercial coal $p$ produced by coal washing plant $j$ \\
\hline$E_{p k}$ & Lowest rate to meet the demand of customer $k$ for the product $p$ \\
\hline$F_{p k}$ & Minimum requirements for coal ash \\
\hline$\underline{Q_{p k}}$ & Amount of coal $p$ which is sold to the customer $k$ \\
\hline Decision Variable & Definition \\
\hline$\overline{Y_{i}}$ & 1 if mine $i$ is open; 0 otherwise \\
\hline$Y_{j}$ & 1 if washing plant $j$ is open; 0 otherwise \\
\hline$Y_{w}$ & 1 if warehouse $w$ is open; 0 otherwise \\
\hline $\mathrm{X}_{\text {pij }}$ & Amount of raw coal transported from mine $i$ to coal washing plant $j$ for product $p$ \\
\hline $\mathrm{X}_{p j w}$ & Amount of product $p$ transported from coal washing plant $j$ to warehouse $w$ \\
\hline$X_{p w k}$ & Amount of product $p$ transported from warehouse $w$ to customer $k$ \\
\hline
\end{tabular}




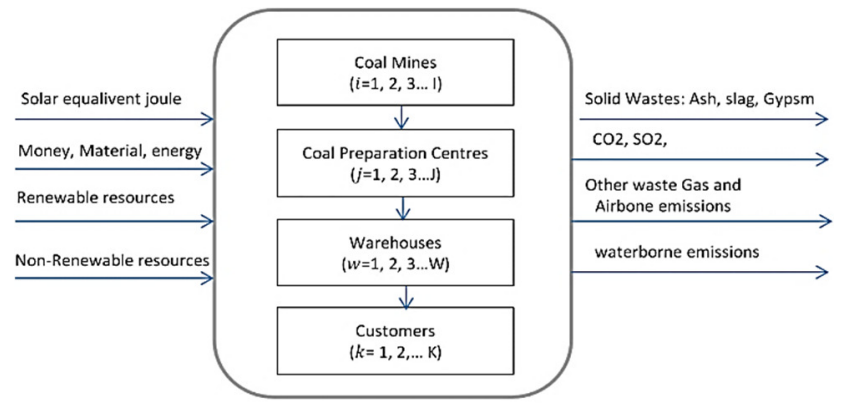

Fig. 2 System boundary of coal supply chain model

\section{Exergy modelling}

Based on the first thermodynamic law, energy can be transformed but it is always conserved. However, exergy is consumed in any process as entropy is generated (second thermodynamic law) [23]. Exergy quantifies the usefulness of energy, and can be defined as the quality of energy, available energy or available work [24]. According to [25], the consumed exergy can be expresses as Eq. (1), where $\delta E x$ is the consumed exergy (MJ), $T_{0}$ is the temperature of surroundings $(\mathrm{K})$, and $S$ is entropy $(\mathrm{MJ} / \mathrm{K})$.

$$
\delta E x=T_{0} \sum \Delta S
$$

Based on the second thermodynamic law, all natural or man-made processes suffer from inevitable shortfalls, inefficiencies and destructed exergy accounts due to the gradually generated entropy [26]. The destructed exergy in a system can be calculated as the difference between the total exergy entering the system and the total exergy leaving the system [27]. According to Guoy-Stodola theorem [28], the exergy destruction $E x_{\text {dest }}$ can be computed from a knowledge of the entropy generated in the system $S_{\text {gen }}$ as

$$
E x_{\text {dest }}=T_{0} . S_{\text {gen }}
$$

As mentioned in [1], the relationship between the vendor and buyer can be modelled as two series heat pumps, while the price is analogues to temperature. Moreover, work (money) is generated by heat pump (vendor). The required work to operate a production process includes the cost of energy, physical equipment, labor, and transportation. As inefficiencies result in wastage of the resources, exergy analysis can be effectively used to enhance the efficiency of the system, and consequently, improve both economic and environmental performances. In summary, entropy in a thermal system can be expressed as Eq. (3), where $Q C_{1}$ is the heat energy extracted from the colder environment at temperature $T C_{1}$, and $\mathrm{QH}_{2}$ is the heat energy rejected at temperature $\mathrm{TH}_{2}$.

$$
S_{\text {gen }}=\frac{Q H_{2}}{T H_{2}}-\frac{Q C_{1}}{T C_{1}}
$$

In this paper, the same analogous as in Jawad et al. [1] is used to present the entropy (destructed exergy) in coal supply chain. It is assumed that the buyer in the coal supply chain represents the surroundings, while the market is represented as the environment. The wasted energy, raw materials, capital, and labor efforts, that may not be regenerated, are represented as entropy. The generated entropy due to product $p$ can be formulated similar to the thermal system, as Eq. (4), where $D_{p}$ is the total demands for product $p$.

$$
S_{g e n}=\frac{D_{p} C_{p}}{C_{p 0}}-\frac{D_{p} \gamma_{p i}}{\bar{\gamma}_{p i}}
$$

Therefore, according to the Guoy-Stodola theorem [28] and the heat pump model [4], the destroyed exergy is equal to $C_{p} S_{g e n}$, and can be expressed as:

$$
E x_{\text {dest }}=C_{p} S_{\text {gen }}=C_{p} D_{p}\left(\frac{C_{p}}{C_{p 0}}-\frac{\gamma_{p i}}{\bar{\gamma}_{p i}}\right)
$$

\section{Multi-objective optimization function}

By extending Eq. (5) considering the process model and applying the mentioned assumptions, economic cost Cos$t_{E C}$ comprising seven elements can be expressed as fixed operation costs at mines (Eq. 6), washing plants (Eq. 7), and warehouses (Eq. 8), inventory cost at washing plants and warehouses (Eq. 9), and variable transportation costs between mines and washing plants (Eq. 10), washing plants and warehouses (Eq. 11), and warehouses and customers (Eq. 12). Therefore, multi-objective function, ObjFun1, considering economic factors can be formulated as Eq. (13).

$$
\begin{gathered}
F_{1}=\sum_{i} f_{i} Y_{i} \\
F_{2}=\sum_{j} f_{j} Y_{j} \\
F_{3}=\sum_{w} f_{w} Y_{w} \\
F_{4}=\sum_{p}\left(\sum_{j} h_{p j} I_{p j} Y_{j}+\sum_{w} h_{p w} I_{p w} Y_{w}\right) \\
F_{5}=\sum_{p} \sum_{i} \sum_{j}\left(\gamma_{p i}+\tau_{i j} r_{i j}\right) X_{p i j} Y_{i} \\
F_{6}=\sum_{p} \sum_{j} \sum_{w}\left(\gamma_{p j}+\tau_{j w} r_{j w}\right) X_{p j w} Y_{j} \\
F_{7}=\sum_{p} \sum_{w} \sum_{k}\left(\gamma_{p w}+\tau_{w k} r_{w k}\right) X_{p w k} Y_{w} \\
\operatorname{Min} \text { ObjFun } 1= \\
\left\{\begin{array}{c}
\sum_{i} f_{i} Y_{i}+\sum_{j} f_{j} Y_{j}+\sum_{w} f_{w} Y_{w}+\sum_{p}\left(\sum_{j} h_{p j} I_{p j} Y_{j}+\sum_{w} h_{p w} I_{p w} Y_{w}\right) \\
+\sum_{p} \sum_{i} \sum_{j}\left(\gamma_{p i}+\tau_{i j} r_{i j}\right) X_{p i j} Y_{i}+\sum_{p} \sum_{j} \sum_{w}\left(\gamma_{p j}+\tau_{j w} r_{j w}\right) X_{p j w} Y_{j} \\
+\sum_{p} \sum_{w} \sum_{k}\left(\gamma_{p w}+\tau_{w k} r_{w k}\right) X_{p w k} Y_{w}
\end{array}\right\}
\end{gathered}
$$

The objective function ObjFun1 of Eq. (13) considers only the workflow of related costs. To be able to include the indirect process costs including the losses due to the disorders in the process (entropy) to the optimization problem, the destructed exergy cost Cost ${ }_{D E}$ of the system can be expressed based on the exergy analysis as:

$$
F_{8}=\sum_{p} \sum_{i} \sum_{k} \partial C_{p} D_{p k}\left(\frac{c_{p}}{C_{p 0}}-\frac{\gamma_{p i}}{\tilde{\gamma}_{p i}}\right) Y_{i}
$$

As a result, the multi-objective function of the sustainable coal supply chain model, ObjFun2 considering both economic and exergetic factors can be expressed as:

$$
\begin{gathered}
\text { Min: ObjFun2 }= \\
\left\{\begin{array}{l}
\sum_{i} f_{i} Y_{i}+\sum_{j} f_{j} Y_{j}+\sum_{w} f_{w} Y_{w}+\sum_{p}\left(\sum_{j} h_{p j} I_{p j} Y_{j}+\sum_{w} h_{p w} I_{p w} Y_{w}\right) \\
+\sum_{p} \sum_{i} \sum_{j}\left(\gamma_{p i}+\tau_{i j} r_{i j}\right) X_{p i j} Y_{i}+\sum_{p} \sum_{j} \sum_{w}\left(\gamma_{p j}+\tau_{j w} r_{j w}\right) X_{p j w} Y_{j} \\
+\sum_{p} \sum_{w} \sum_{k}\left(\gamma_{p w}+\tau_{w k} \gamma_{w k}\right) X_{p w k} Y_{w} \\
+\sum_{p} \sum_{i} \sum_{k} \partial C_{p} D_{p k}\left(\frac{c_{p}}{c_{p 0}}-\frac{\gamma_{p j}}{\bar{\gamma}_{p i}}\right) Y_{i}
\end{array}\right\}
\end{gathered}
$$

The boundary conditions of the optimization problem can be represented by Eqs. (16) to (25). Equations (16) to (18) are capacity constraints that control the maximum flows. Equations (19) to (21) define the logistics balance and constraints of the coal supply chain system. It is obvious that for each product, the inbound flow should be equal to the sum of all outbound flows at each node. Equation (19) represents the quantity balance at the production facilities and assure the flow balance between the mines and the coal washing plants. Equation (20) is the quantity balance of raw coal at washing plants. Equation (21) is related to the coal sale balance. Equation (22) defines the 
constraints of the customer demands to ensure that all demands for products are completely fulfilled. Equation (23) is about the customers quality requirements. Finally, constraints (24) and (25) enforce the binary and non-negativity restrictions on the decision variables, respectively.

$$
\begin{gathered}
\sum_{j} x_{p i j} \leq \alpha_{p i} Y_{i}, \forall p, i \\
\sum_{w} x_{p j w} \leq \alpha_{p j} Y_{j}, \forall p, j \\
\sum_{k} x_{p w k} \leq \alpha_{p w} Y_{w}, \forall p, w \\
\sum_{i} x_{p i j}=\sum_{j} x_{p j w}+\sum_{j} S H_{p j} \forall p, w \\
\sum_{j} x_{p j w}=\sum_{w} x_{p w k} \forall p, k \\
Q_{p k}=\sum_{w} x_{p w k}, \forall p, k \\
D_{p k} E_{p k} \leq \sum_{w} x_{p w k} \leq E_{p k} \forall p, k \\
\sum_{j} x_{p j w} S H_{p j} \leq Q_{p k} F_{p k} \\
Y_{i}, Y_{j}, Y_{w} \in\{0,1\} \\
x_{p i j}, x_{p j w}, x_{p w k} \geq 0
\end{gathered}
$$

In order to solve the problem and find the minimum economic and exergetic costs of the sustainable coal supply chain model, ObjFun2 of Eq. (15) should be solved together with fulfilling constrains of Eqs. (16) to (25).

\section{Model assumptions}

In the case of gross coal, various types of coal can be obtained, intended for different energy applications. The selling price of various products to various customers is different, e.g., due to bonus. Moreover, all facilities and washing plants are under aging effects that will cause some additional costs to the supply chain. However, to simplify the problem, the following assumptions have been made:

1. There is only one specific product, i.e., prepared coal.

2. The selling price to all customers is assumed to be the same.

3. It is assumed that the washing plant is new and the aging effects are neglected.

4. It is assumed that all washing plants are using the same coal washing technology.

\section{Solution method based on genetic algorithm}

The complexity of the supply chain design problem is known to be NP-hard [29]. Therefore, the proposed sustainable coal supply chain combined with the ecological impact aspects is also a NP-hard problem. The available techniques for NP-hard problems can be classified into exact, heuristic, and metaheuristic methods [30]. Exact algorithms (e.g., branch \& bound) are guaranteed to find an optimal solution. However, the size of search space and consequently required run-time increases dramatically with the instance size, and thus, only small instances can be practically solved using exact methods [31]. Therefore, the only possibility for real-world applications with medium/large instances is to utilize heuristic or metaheuristic algorithms.

Heuristics (e.g., greedy algorithms) are problem-dependent techniques specifically developed to the problem with inspiration from available information in system model [32]. Greedy algorithms built a solution piece by piece, making the locally optimal choice at each stage [33]. Heu- ristic algorithms cannot usually produce an optimal solution, as they don't explore the whole search space, nonetheless it may yield locally optimal solutions in a reasonable amount of time [34]. However, metaheuristic algorithms can provide a more robust solution at the expense of increased computational efforts for globally searching among the search space [35]. Since genetic algorithm (GA) has proved its efficiency in solving different supply chain problems in different studies with a satisfactory performance [36, 37, 38, 39], we utilize GA to solve the proposed model for sustainable coal supply chain management including the economic and exergetic objectives.

The flowchart of the proposed GA can be seen in Fig. 3.

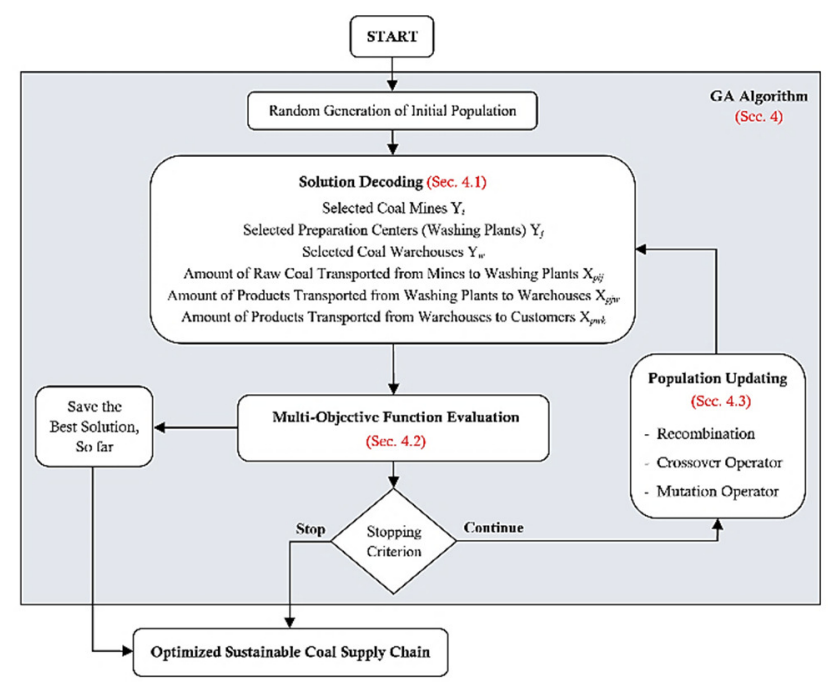

Fig. 3 Overall flowchart of the proposed GA

The GA procedure starts by generating a random initial population of chromosomes (feasible solutions) according to the encoding scheme (Sec. 4-1), each contains three binary structures $Y_{i}, Y_{j}$, and $Y_{w}$, and three integer structures $X_{p i j}, X_{p j w}$, and $X_{p w k}$. Then, multi-objective function evaluation (Sec. 4-2) and population updating (Sec. 4-3) are successively done until the stop criterion (completion of the maximum iterations) reaches. The detail of the proposed GA is provided in the following.

A feasible solution of the problem can be represented as a hybrid binary-integer structure comprising three binary and three integer matrices. As shown in Fig. 4, decision variables of the optimization problem include

1. Choosing a subset of mines to supply raw coals $Y_{i}$ is a binary vector of length $I$.

2. Selecting a subset of washing plants $Y_{j}$ is a binary vector of length $J$.

3. Selecting a subset of coal warehouses $Y_{w}$ is a binary vector of length $W$.

4. Amounts of raw coals transported from mines to washing plants $X_{p i j}$ is an integer matrix of dimension IXJ.

5. Amounts of products transported from washing plants to warehouses $X_{p j w}$ is an integer matrix of dimension $J \times W$.

6. Amounts of products transported from warehouses to customers $X_{p w k}$ is an integer matrix of dimension $W \times K$. 


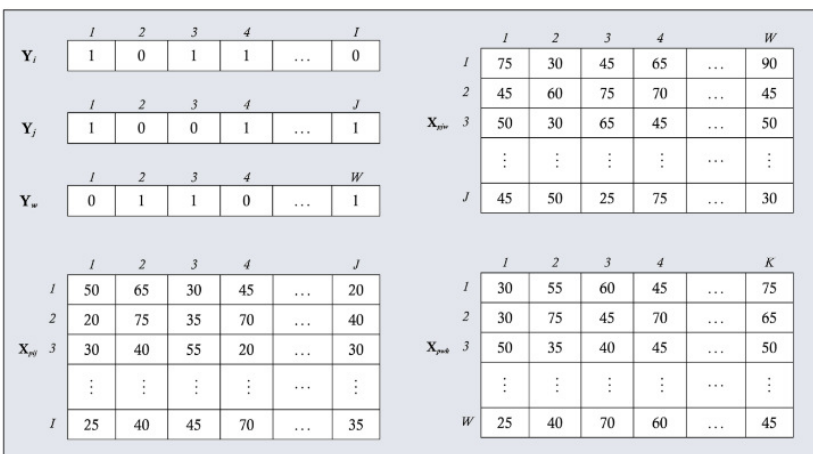

Fig. 4 Encoding of a feasible solution (a chromosome)

At every iteration, each chromosome is decoded according to Fig. 4, and then, is evaluated according to the multiobjective function ObjFun as in Eq. (15). Moreover, all constraints are checked to be verified or not. As a result, the overall cost of each chromosome can be calculated as COST $=$ ObjFun $\times 2^{\mathrm{PF}}$, where PF is the total number of constraints of Eqs. (15) to (24) which have not been fulfilled (penalty function). Population updating includes recombination, crossover and mutation which produce $P_{R}, P_{C}$, and $P_{M}$ percentages, respectively. These rates are considered as $P_{R}=10 \%, P_{C}=50 \%$ and $P_{M}=40 \%$. In recombination phase, all chromosomes are sorted from the best to the worst according to their COST, and then, $P_{R} \%$ of the best solutions are directly transferred to the next generation. In order to generate an offspring using crossover operator, at first, two chromosomes are selected via a parent selection strategy, and then, uniform crossover operator is applied for each binary or integer structure of the selected parents. In uniform crossover, each gene of the structure is transferred from the same gene of parent 1 or parent 2 , each by a probability of $50 \%$. In mutation phase, a chromosome is selected by the EPS, and then, a gene is randomly selected and mutated. Based on the hybrid binary-integer structure of the solutions, either binary swap mutation or integer mutation is performed on the selected gene of the binary or integer structure.

\section{Time complexity analysis}

Typically, time complexity of any population-based metaheuristic algorithm can be expressed as O(MaxIterx (PopSizexTC $\left.C_{o b j F u n}+T C_{\text {Pop Up }}\right)$ ), where PopSize is the population, Maxlter is the maximum number of iterations, $T C_{O b j F u n}$ is the time complexity required for the objective function evaluation for a single solution at any iteration (a chromosome), and $T C_{\text {Popup }}$ is the time complexity required for the population updating in one iteration (include recombination, crossover, and mutation). For complex models including many objectives and constraints (like the present model), the time complexity required at every iteration of the algorithm for the population updating can be neglected against the time complexity of the objective function evaluation. Therefore, the time complexity of the proposed GA can be simplified as O(MaxlterxPopSizexT(ObjFun). Based on the system model of sustainable coal supply chain in Sec. 3-4, one objective function evaluation has a time complexity of $O(I \times J \times W \times K)$. Therefore, the time complexity of the proposed GA can be simplified as $O($ Maxlter $\times$ PopSize $\times 1 \times J \times W \times K)$.

\section{RESULTS OF RESEARCH}

The proposed model and the solution method based on GA have been successfully coded in MATLAB R2019b environment. The experiments were executed on a PC with Quad Core $2.4 \mathrm{GHz}$ processor and $8 \mathrm{~GB}$ RAM running on windows 10 . In order to performance evaluation of the proposed method, it has been tested on three datasets considering different complexities. Moreover, to understand the effectiveness of the exergy analysis, the model is solved under two times: one by considering both economic and destructed exergy costs of Eq. (15), and another by considering only the economic costs of Eq. (13) as objective function of $G A$.

Parameter setting of the GA is summarized in Table 2. To adjust each controllable parameter of the algorithm, different values were evaluated, and the best value in term of convergence speed and total cost was determined for final simulations. Population size and maximum iterations were considered as 50 and 500, respectively. The percentage of the population achieved by recombination, crossover, and mutation, were set as $P_{R}=10 \%, P_{C}=50 \%$ and $P_{M}=40 \%$. Different selection strategies, i.e., Roulette Wheel Selection (RWS), Tournament Selection (TS), and Elitism Parent Selection (EPS) were evaluated. Among them, EPS was chosen, because of better performance in terms of total cost and convergence speed. Moreover, binary swap and integer operators were chosen for the mutation in the hybrid binary-integer structure of the algorithm.

Table 2

Dimension of coal supply chain datasets

\begin{tabular}{ccccc}
\hline $\begin{array}{c}\text { Dataset } \\
\#\end{array}$ & Mines & $\begin{array}{c}\text { Washing } \\
\text { Plants }\end{array}$ & Warehouses & Customers \\
\hline 1 & 5 & 5 & 10 & 10 \\
2 & 10 & 15 & 20 & 25 \\
3 & 15 & 25 & 30 & 40 \\
\hline
\end{tabular}

In order to validate the proposed method, three coal supply chain datasets were used with different complexities. Details of these datasets in term of the number of coal mines, washing plants, warehouses, and customers can be seen in Table 2. The model parameters were generated using uniform distributed random values according to valid ranges as summarized in Table 3.

These parameters are considered based on real ranges of data provided in Iran Ministry of Industry, Mine and Trade [40] and Iranian Mines and Mining Industries Development and Renovation Organization, IMIDRO [41]. It is mentioned that annual coal production capacity in Iran is around 1.5 million tons ( 3 million tons of raw coal). However, because of improper situation of the market and absence of investment for the purchase of equipment and lack of preparation of the mines, the actual coal productions had been lower than its capacity in last years. 
Table 3

Table 4

Details of parameters in the datasets

\begin{tabular}{lc}
\hline \multicolumn{1}{c}{ Parameter } & $\begin{array}{c}\text { Uniform Distribution } \\
\text { or Rate }\end{array}$ \\
\hline Demands & $10,000-50,000$ (ton) \\
Market Prices & $150-250$ (USD/ton) \\
Unit market purchasing price & $60-90$ (USD/ton) \\
for raw coal & $100,000-300,000$ (ton) \\
Mine capacity of raw coal & $50,000-200,000$ (ton) \\
Production capacity & $100,000-300,000$ (ton) \\
Capacity of other stages & $\% 10$ of production \\
Minimum requirements & capacity \\
for coal ash & $1,000,000-2,000,000$ \\
Fixed cost of coal mines & (USD) \\
Fixed cost of washing plants & $500,000-1,000,000$ (USD) \\
Fixed cost of warehouses & $100,000-200,000$ (USD) \\
Unit raw coal mine cost & $30-50$ (USD/ton) \\
Unit production cost & $100-150$ (USD/ton) \\
at washing plants & $4-7$ (USD/ton) \\
Unit variable cost at warehouses & $3-5$ (USD/ton) \\
Unit inventory holding cost & \\
at washing plants & $2-3$ (USD/ton) \\
Unit inventory holding cost & \\
at warehouses & 1.5 (USD/ton/Km) \\
Unit transportation cost between & \\
mines and washing plants & 2 (USD/ton/Km) \\
Unit transportation cost between & other stages
\end{tabular}

But according to Deputy for Mine and Mineral Industries Projects at IMIDRO, some plans and new projects are designed in 2019 for attracting private sector investment in the construction of coal washing factories and development of coal mines. For example there are projects to equip and for construction of coal washing factories in Savadkouh (Central Alborz), Shahroud (Semnan Province) of Iran with production capacity of 150 and 200 thousand tons [41].

\section{Simulation results}

In order to understand the effectiveness of considering the exergetic cost in our model, two scenarios are simulated. To achieve this purpose, the result of the economic objective function ObjFun1 in Eq. (13) is compared with that of the proposed economic-exergetic objective function ObjFun2 in Eq. (15). Because of random nature of search process in metaheuristic algorithms, the proposed GA was run 10 times for each dataset under the two scenarios.

The average results (over 10 runs) of the economic cost (Cost $t_{E C}$ ) and the destructed exergy cost (Cost ${ }_{D E}$ ) can be summarized in Table 4.

Although by considering economic-exergetic model of $\mathrm{Ob}$ jFun2, economic costs are a little bit more than those of in the economic model of ObjFun1, efficient saving in destructed exergy costs can be obtained. From time complexity of view, considering the proposed economic-exergetic model increases the CPU running time for only about 3 to 6 seconds for the different datasets, which can be ignored.

Computational results of different costs (in millions) and CPU time (in seconds)

\begin{tabular}{ccccccc}
\hline $\begin{array}{c}\text { Da- } \\
\text { taset \# }\end{array}$ & \multicolumn{2}{c}{ Optimization of ObjFun1 } & \multicolumn{3}{c}{$\begin{array}{c}\text { Optimization of ObjFun2 } \\
\text { (Proposed) }\end{array}$} \\
& Cost $_{\mathrm{EC}}$ & Cost $_{\mathrm{DE}}$ & $\begin{array}{c}\text { CPU } \\
\text { Time }\end{array}$ & Cost $_{\mathrm{EC}}$ & Cost $_{\mathrm{DE}}$ & $\begin{array}{c}\text { CPU } \\
\text { Time }\end{array}$ \\
\hline 1 & 55.7 & 14.9 & 105 & 57.2 & 12.4 & 108 \\
2 & 105.9 & 27.1 & 149 & 108.6 & 22 & 154 \\
3 & 162.5 & 46.9 & 191 & 167.3 & 38.7 & 197 \\
\hline
\end{tabular}

In order to capture the convergence speed of the proposed GA, the diagram for dataset 2 is provided in Fig. 5 . As seen in Fig. 5, the final cost of the GA is achieved as 130.6 million USDs, which can be calculated by the summation of Cost $_{E C}$ (108.6 million) and Cost ${ }_{D E}$ (22 million).

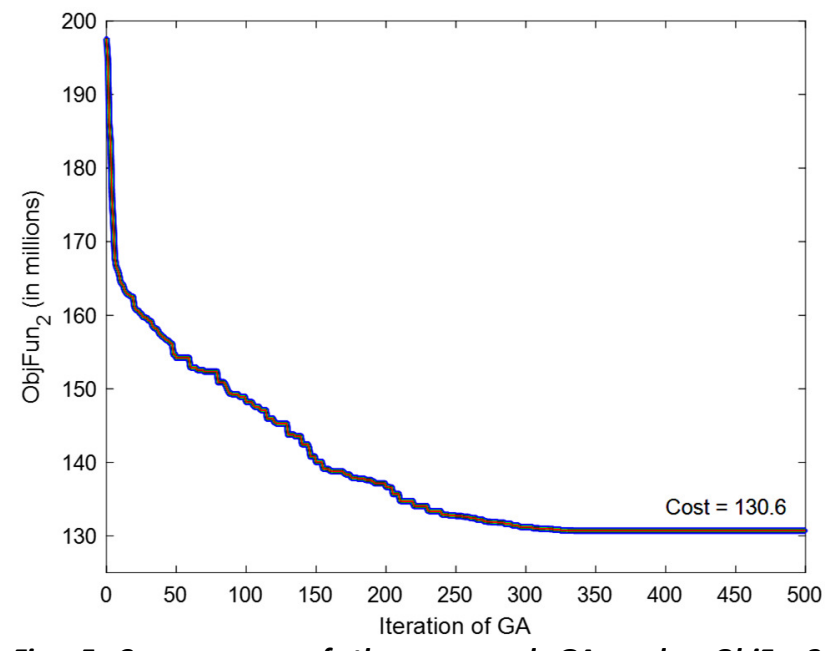

Fig. 5 Convergence of the proposed GA under ObjFun2 for dataset 2

In order to better understanding the effect of considering the destructed exergy into the multi-objective function of the algorithm, the results of two scenarios are compared in Table 5 and Fig. 6.

Table 5

Effects of economic-exergetic objective function ObjFun2 against ObjFun1

\begin{tabular}{|c|c|c|c|c|c|c|}
\hline \multirow{2}{*}{$\begin{array}{c}\text { Dataset } \\
\#\end{array}$} & \multicolumn{2}{|c|}{$\begin{array}{c}\text { Additional Eco- } \\
\text { nomic Cost }\end{array}$} & \multicolumn{2}{|c|}{$\begin{array}{c}\text { Saving in Exergy } \\
\text { Cost }\end{array}$} & \multicolumn{2}{|c|}{$\begin{array}{c}\text { Additional CPU } \\
\text { Time }\end{array}$} \\
\hline & Value & $\%$ & Value & $\%$ & Value & $\%$ \\
\hline 1 & 1.5 & 2.7 & 2.5 & 16.4 & 3 & 2.8 \\
\hline 2 & 2.7 & 2.5 & 5.1 & 18.8 & 5 & 3.3 \\
\hline 3 & 4.8 & 3 & 8.2 & 17.5 & 6 & 3.1 \\
\hline Average & 3 & 2.7 & 5.26 & 17.6 & 4.67 & 3.06 \\
\hline
\end{tabular}

By considering the destructed exergy in the proposed model, significant saving in the destructed exergy cost (Cost ${ }_{D E}$ ) can be obtained by accepting additional economic cost (Costec). According to the results in Fig. 6, the proposed economic-exergetic model on average can save $17.6 \%$ (5.26 million) in the destructed exergy by consuming $2.7 \%$ (3 million) more economic costs. 


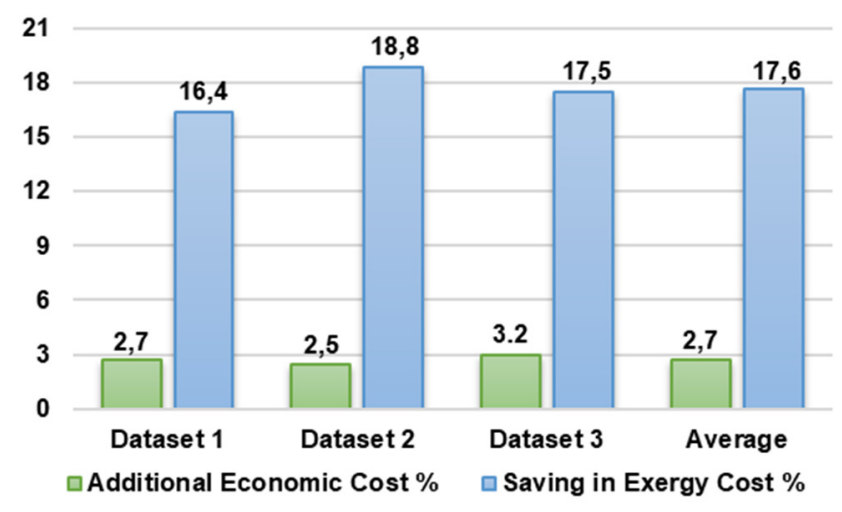

Fig. 6 Saving in exergy cost \% by accepting additional economic cost \%

\section{Sensitivity analysis}

In this section, a sensitivity analysis is provided by changing the default values of the system model. To achieve this purpose, $20 \%$ reduction in the variable cost of production, $20 \%$ reduction in warehouse costs, and $20 \%$ reduction in the coal demands. The obtained results for dataset 2 can be summarized in Table 6, in term of the total cost (ObjFun2) and the eight elements of the objective function. All changes greater than $10 \%$ are shown in bold. According to the obtained results in Table 6, reduction in production costs has a great effect on reducing operation costs at washing plants $\left(F_{2}\right)$, while reduction in warehouse costs reduces operation costs at warehouses $\left(F_{3}\right)$ and inventory cost (F4). Reduction in coal demands leads to reduction in more stages of the supply chain: operation costs at washing plants $\left(F_{2}\right)$, transportation costs between washing plants and warehouses $\left(\mathrm{F}_{6}\right)$, transportation costs between warehouses and customers $\left(\mathrm{F}_{7}\right)$, and destructed exergy cost $\left(\mathrm{F}_{8}\right)$. As a result, by $20 \%$ reduction in coal demands, the total cost is reduced from 130.6 million to 116.5 million, and consequently, $10.8 \%$ of the total cost of the sustainable coal supply chain can be saved.

Table 6

Sensitivity analysis for dataset 2 for different cases

\begin{tabular}{|c|c|c|c|c|}
\hline \multirow[b]{2}{*}{ Cost Function } & \multirow[b]{2}{*}{$\begin{array}{l}\text { Default } \\
\text { Values } \\
\text { (in mil- } \\
\text { lions) }\end{array}$} & \multicolumn{3}{|c|}{ Sensitivity Analysis under } \\
\hline & & $\begin{array}{l}20 \% \\
\text { Reduction } \\
\text { in Produc- } \\
\text { tion Costs }\end{array}$ & $\begin{array}{c}20 \% \\
\text { Reduction } \\
\text { in Ware- } \\
\text { house Costs }\end{array}$ & $\begin{array}{c}20 \% \\
\text { Reduction } \\
\text { in Coal } \\
\text { Demands }\end{array}$ \\
\hline$F_{1}$ (Eq. 6) & 12.35 & 12.2 & 12.6 & 11.6 \\
\hline$F_{2}$ (Eq. 7) & 6.11 & $\begin{array}{c}5.12 \\
(-16.2 \%)\end{array}$ & 6.07 & $\begin{array}{c}5.27 \\
(-13.7 \%)\end{array}$ \\
\hline $\mathrm{F}_{3}$ (Eq. 8) & 2.5 & 2.48 & $\begin{array}{c}2.21 \\
(-11.6 \%)\end{array}$ & 2.31 \\
\hline $\mathrm{F}_{4}$ (Eq. 9) & 1.26 & 1.23 & $\begin{array}{c}1.13 \\
(-10.3 \%)\end{array}$ & 1.32 \\
\hline$F_{5}($ Eq. 10) & 22.4 & 20.8 & 22.72 & 20.7 \\
\hline $\mathrm{F}_{6}$ (Eq. 11) & 58.3 & 56.8 & 57.2 & $\begin{array}{c}52.4 \\
(-10.1 \%)\end{array}$ \\
\hline$F_{7}$ (Eq. 12) & 5.7 & 5.53 & 5.27 & $\begin{array}{c}4.66 \\
(-18.3 \%)\end{array}$ \\
\hline $\mathrm{F}_{8}$ (Eq. 14) & 22 & 22.4 & 21.8 & $\begin{array}{c}18.2 \\
(-17.3 \%)\end{array}$ \\
\hline Total Cost (Eq. 15) & 130.6 & 126.5 & 129 & 116.5 \\
\hline $\begin{array}{l}\text { Reduction } \\
\text { in Total Cost (\%) }\end{array}$ & N/A & $3.1 \%$ & $1.2 \%$ & $10.8 \%$ \\
\hline
\end{tabular}

\section{DISCUSSION}

In order to have sustainable supply chain management, it is of utmost importance to pay more attention to the exergy removed from the nature and consider the environmental impacts of any product or services especially for those which create more pollution like coal extraction, processing and consumption. The obtained results show the ability of the proposed model to help the supply chain decision makers to decide about the best choices for having a profitable supply chain besides, less destroying the environment and approaching to more sustainable coal supply chain. There is an additional economic cost as showed above, but the benefit of the model is that it will help decision makers to quantify this additional cost which is necessary for further decisions.

Table 7 provides the mass of the material resources, emissions and wastes to produce one tonne of raw coal [42]. Therefore, by proper optimization of the coal supply chain, more sustainability and less environmental destruction from renewable and non-renewable resources can be obtained.

Table 7

Environmental impacts to produce one tonne of raw coal

\begin{tabular}{llc}
\hline & \multicolumn{1}{c}{ Item } & Quantity (kg) \\
\hline \multirow{4}{*}{ Renewable Resources } & Oxygen & 185 \\
& Freshwater & 402 \\
& Salt & 1.6 \\
& Limestone & 0.51 \\
& Clay & 0.0054 \\
& Sand & 0.087 \\
Non-Renewable Resources & Gravel & 0.047 \\
& Natural gas & 0.13 \\
& Hard coal & 1230 \\
Emissions & Oil & 4 \\
& Co 2 & 0.41 \\
Solid Wastes & No & 0.29 \\
& So & 2.48 \\
& Ash & 0.32 \\
& Slag & 0.26 \\
& Gypsum & 98.1 \\
\hline
\end{tabular}

\section{CONCLUSION}

To design a new coal supply chain process or optimize an existing one, some decisions should be made such as choosing the number, capacity, and the technology used for different network facilities. The current study has proved that exergy concept can be effectively used to formulate the total cost of the system including the destructed exergy. It can provide an insight about the potential of environmental destruction saving per unit of additional economic costs. It would be extremely beneficial at the time of business case calculation for the new projects or modification and upgrading the current coal supply chain, in order to minimize economic costs while protect the environment.

In this paper, it was assumed that there is only one specific product (i.e., prepared coal). However, in the case of gross coal, various types and assortments of coal can be obtained. Moreover, the selling price was considered to be the same for all customers. It was also assumed that all 
facilities are new that is possible only in the case of new projects and large mining investments in completely new coal basins. As a future work, the proposed model can be extended to various types of coal products with different selling prices to different customers, considering aging effects of facilities. Another suggestion for further improvement of this model is to investigate the impact of machineries aging on pollution and the impact of different technologies on the consumed exergy. Using the real data of the coal mines in developing countries and investigate the exergy destructions would be another interesting topic for future study.

\section{REFERENCES}

[1] H. Jawad, M.Y. Jaber and R.Y. Nuwayhid. "Improving supply chain sustainability using exergy analysis". European Journal of Operational Research, Vol. 269(1), pp. 258-271, 2018.

[2] S. Yang and Y. Qian. "The inclusion of economic and environmental factors in the ecological cumulative exergy consumption analysis of industrial processes". Journal of Cleaner Production, vol. 108, pp. 1019-1027, 2015.

[3] A. Muchtar. "Preliminary Analysis of Single-Flash Geothermal Power Plant by Using Exergy Method. Case Study: Ulubelu Geothermal Power Plant-Indonesia". International Journal of Renewable Energy Research (IJRER), vol. 8(3), pp. 1685-1696, 2018.

[4] A.A. Ojo, O. Awogbemi, and A.O. Ojo. "An Overview of the Exploitation of Renewable Energy Resources in Nigeria, South Africa, and the United Kingdom". International Journal of Renewable Energy Research (IJRER), vol. 10(2), pp. 843-861, 2020

[5] S. Nyquist. "Energy 2050: Insights from the ground up". McKinsey \& Company, 2016.

[6] F. Freme. "US Coal supply and demand: 2009 review". Electric Power, Vol. 922(937.8), pp. 946-8, 2009.

[7] US Energy Information Administration (Ed.). (2011). Annual Energy Outlook 2011: With Projections to 2035. Government Printing Office.

[8] J. Phillips, (2008). Modeling the US Coal Supply Chain. Colorado School of Mines. Retrieved from http://dahl. mines. edu/coalphillips. pdf,(last accessed in June 2012).

[9] S. Mehmood, B.V. Reddy and M.A. Rosen. "Exergy analysis of a biomass co-firing based pulverized coal power generation system". International journal of green energy, vol. 12(5), pp. 461-478, 2015.

[10] T. Aniokete, M. Ozonoh, and M.O. Daramola. "Synthesis of Pure and High Surface Area Sodalite Catalyst from Waste Industrial Brine and Coal Fly Ash for Conversion of Waste Cooking Oil (WCO) to Biodiesel". International Journal of Renewable Energy Research (IJRER), vol. 9(4), pp. 19241937, 2019.

[11] L. Man-Zhi, Z. Mei-Hua, L. Xue-Qing, and Y. Ji-Xian. "The research on modeling of coal supply chain based on objectoriented Petri net and optimization". Procedia Earth and Planetary Science, vol. 1(1), pp. 1608-1616, 2009.

[12] A. Thomas, J. Venkateswaran, G. Singh and M. Krishnamoorthy. "A resource constrained scheduling problem with multiple independent producers and a single linking constraint: A coal supply chain example". European Journal of Operational Research, vol. 236(3), pp. 946-956, 2014.

[13] L. Pan, P. Liu, L. Ma and Z. Li. "A supply chain based assessment of water issues in the coal industry in China". Energy Policy, vol. 48, pp. 93-102, 2012.
[14] A. Thomas, J. Venkateswaran, G. Singh and M. Krishnamoorthy. "A resource constrained scheduling problem with multiple independent producers and a single linking constraint: A coal supply chain example". European Journal of Operational Research, vol. 236(3), pp. 946-956, 2014.

[15] H. Jawad, M.Y. Jaber, M. Bonney and M.A. Rosen "Deriving an exergetic economic production quantity model for better sustainability". Appl. Math. Model. vol. 40, pp. 60266039, 2016.

[16] A. Baral, B.R. Bakshi, and R.L. Smith. "Assessing resource intensity and renewability of cellulosic ethanol technologies using Eco-LCA". Environmental science \& technology, vol. 46(4), pp. 2436-2444, 2012.

[17] I. Manisalidis, E. Stavropoulou, A. Stavropoulos and E. Bezirtzoglou. "Environmental and health impacts of air pollution: A review". Frontiers in public health, vol. 8, 2020.

[18] International Energy Agency, Data and Statics: https://www.iea.org/data-and-statistics. July. 01, 2020 [July. 01, 2020].

[19] M. Mann and P. Spath. "A life cycle assessment of biomass cofiring in a coal-fired power plant". Clean Products and Processes, vol. 3(2), pp. 81-91, 2001.

[20] J. Bijańska and K. Wodarski. "Model of process management system in enterprises of the hard coal mining industry". Management Systems in Production Engineering, vol. 28(2), pp. 112-120, 2020.

[21] C. Wang, D. Mu. "An LCA study of an electricity coal supply chain". Journal of Industrial Engineering and Management, vol. 7(1), pp. 311-335, 2014.

[22] S. Bhagwat, X. Zhang and H. Fan. "Estimation of coal cleaning costs: a spreadsheet based interactive software for use in estimation of economically recoverable cost reserves". US Geological Survey Professional. pp. 1-13, 2009.

[23] M.E. Bösch, S. Hellweg, M.A. Huijbregts and R. Frischknecht. "Applying cumulative Exergy demand (CEXD) indicators to the ecoinvent database". The International Journal of Life Cycle Assessment, vol. 12(3), pp. 181-190, 2007.

[24] A. Vadiee and M. Yaghoubi, "Exergy Analysis of the Solar Blind System integrated with a Commercial Solar Greenhouse," International Journal of Renewable Energy Research, vol. 6, no. 3, 2016.

[25] J. Szargut. Exergy method: technical and ecological applications. WIT press, vol. 18, 2005.

[26] R. Leutz, Nonimaging Fresnel Lenses: Design and Performance of Solar Concentrators, Springer Berlin Heidelberg, 2001.

[27] A.J. Mahmood. "An Experimental Study on Energy and Exergy for Glazed and Unglazed Solar System with Perforated Absorber Plate and Wire Mesh Layers". International Journal of Renewable Energy Research (IJRER), vol. 9(4), pp. 1901-1911, 2019.

[28] A. Bejan. Entropy Generation Minimization: The Method of Thermodynamic Optimization of Finite-Size Systems and Finite-Time Processes, CRC Press, 1995.

[29] T. Loukil, J. Teghem, and D. Tuyttens. "Solving multi-objective production scheduling problems using metaheuristics". European journal of operational research, vol. 161(1), pp. 42-61, 2005.

[30] M. Shokouhifar, A. Jalali. "Simplified symbolic transfer function factorization using combined artificial bee colony and simulated annealing". Applied Soft Computing, vol. 55, pp. 436-451, 2017. 
[31] Z.M. Zahedi, R. Akbari, M. Shokouhifar, F. Safaei and A. Jalali. "Swarm intelligence based fuzzy routing protocol for clustered wireless sensor networks". Expert Systems with Applications, vol. 55, pp. 313-328, 2016.

[32] K. Sorensen. "Metaheuristics-the metaphor exposed". International Transactions in Operational Research, vol. 22(1), pp. 3-18, 2015.

[33] P. Festa. "A brief introduction to exact, approximation, and heuristic algorithms for solving hard combinatorial optimization problems". In $201416^{\text {th }}$ International Conference on Transparent Optical Networks (ICTON) pp. 1-20, 2014.

[34] V. Haleh and F. Imam Ibrahim. "Feature Selection Methods: Genetic Algorithms vs. Greedy-like Search". In Proc. Int. Conf. Fuzzy Intell. Control Syst pp. 1-10, 2005.

[35] F. Fanian, V.K. Bardsiri and M. Shokouhifar. "A new task scheduling algorithm using firefly and simulated annealing algorithms in cloud computing". International Journal of Advanced Computer Science and Applications, vol. 9 (2), pp. 195-202, 2018.

[36] A. Saghaeeian, and R. Ramezanian. "An efficient hybrid genetic algorithm for multi-product competitive supply chain network design with price-dependent demand". Applied Soft Computing, vol. 71, pp. 872-893, 2018.

\footnotetext{
Reihaneh Naderi

Semnan University, Semnan

Faculty of Economics, Management

and Administration Sciences

Industrial Management Department, Iran

e-mail: r.naderi@semnan.ac.ir

\author{
Mohsen Shafiei Nikabadi* \\ ORCID ID: 0000-0002-9744-960X \\ Semnan University, Semnan \\ and Administration Sciences \\ Industrial Management Department, Iran \\ e-mail: shafiei@semnan.ac.ir \\ Tel.: +989125404808, Fax: +982331532579 \\ *corresponding autor
}

Faculty of Economics, Management
}

\section{Akbar Alem-Tabriz}

Shahid Beheshti University, Tehran

Faculty of Management and Accounting

Industrial Management Department, Iran

e-mail: a-tabriz@sbu.ac.ir

\section{Mir Saman Pishvaee}

School of Industrial Engineering

Iran University of Science and Technology, Tehran, Iran

e-mail: pishvaee@iust.ac.ir
[37] Y.B. Woo and B.S. Kim. "A genetic algorithm-based metaheuristic for hydrogen supply chain network problem with two transportation modes and replenishment cycles". Computers \& Industrial Engineering, vol. 127, pp. 981-997, 2019.

[38] A. Rostami, M. M. Paydar and E. Asadi-Gangraj. "A Hybrid Genetic Algorithm for Integrating Virtual Cellular Manufacturing with Supply Chain Management Considering New Product Development". Computers \& Industrial Engineering, 2020.

[39] H. Gholizadeh and H. Fazlollahtabar. "Robust Optimization and modified genetic algorithm for a closed loop green supply chain under uncertainty: Case study in Melting Industry". Computers \& Industrial Engineering, 2020.

[40] Iran Ministry of Industry, Mine and Trade: https://en.mimt.gov.ir. July. 10, 2020 [July. 10, 2020].

[41] Iranian Mines \& Mining Industries Development \& Renovation Organization: http://imidro.gov.ir/general_content/2634-coal.html, July. 10, 2020 [July. 10, 2020].

[42] G. Luo, J. Zhang, Y. Rao, X. Zhu and Y. Guo. "Coal Supply Chains: A Whole-Process-Based Measurement of Carbon Emissions in a Mining City of China". Energies, vol. 10 (11), pp. 1855, Nov. 2017; https://doi.org/10.3390/ en10111855. 